\title{
ÉLITES, PATH DEPENDENCYY LA FALTA DE UN PACTO CONSTITUCIONAL ESTABLE EN ChILE y ARgentinA: UN ANÁLISIS COMPARATIVO-HISTÓRICO
}

\author{
Jaime Baeza Freer (jbaezaf@u.uchile.cl) \\ Universidad de Chile
}

La literatura predominante sobre política latinoamericana ha señalado la existencia de path dependency entre los regímenes presidenciales de la región. Sin embargo, este trabajo ofrece una explicación alternativa que incluye en el análisis los valores de poder centralizado, autoridad, orden y preeminencia de la élite, que fueron transformados en instituciones formales, principalmente la Constitución. En consecuencia, decisiones sub-óptimas tomadas en ciertas coyunturas críticas destinadas a mantener el status quo son más relevantes que acuerdos institucionales duraderos, como en el caso de Estados Unidos. La falta de un acuerdo constitucional en América Latina, donde coaliciones políticas coyunturales de la élite con otros sectores sociales impusieron las reformas estructurales, se parece a lo que en economía se ha descrito como el contrato social ausente. Para superar dicha falta, en Chile los sectores no pertenecientes a la élite buscaron métodos democráticos a diferencia que en Argentina donde la democracia se consideró sólo una de las herramientas disponibles. Aunque el resultado inicial del análisis es diferente, hoy en día ambos países enfrentan una falta de acuerdo constitucional similar, que obliga tanto a Argentina como a Chile a continuar esforzándose por lograr instituciones democráticas duraderas.

Palabras clave: élites, presidencialismo, Chile, Argentina. 


\section{ELITES, PATH DEPENDENCY AND THE LACK OF A STABLE CONSTITUTIONAL ARRANGEMENT IN CHILE AND Argentina: A COMPARATIVE-HISTORICAL ANALYSIS}

The core literature on Latin American politics has stressed the existence of path dependency among presidential regimes in the region. However, this paper offers an alternative explanation, where dependence is found in values such as central power, authority, order and elite pre-eminence, which were transformed into formal institutions, principally the Constitution. Consequently, sub-optimal decisions taken at certain critical junctures aimed at maintaining the status quo are more relevant than lasting institutional agreements, as is the case in the United States. The lack of a constitutional agreement resembles what in economics has been described as the missing social contract, where elite or temporary political coalitions with other social sectors imposed structural reforms. In order to overcome this void, Chile's non-elite sectors pursued democratic means, whereas in Argentina this was considered only one of the available tools. Though the initial outcome for analysis is different, both countries currently share the lack of a constitutional agreement, forcing both to continue to search for lasting democratic institutions.

Keywords: elites, presidentialism, Chile, Argentina. 


\section{Introducción ${ }^{1}$}

$\mathrm{E}$

n el caso británico, la monarquía constitucional está basada en las tradiciones

de una Constitución no escrita, pero en donde la prerrogativas reales están siempre sujetas en la existencia de un Parlamento en el cual reside la soberanía, y por cierto, liderados por un Primer Ministro que hace las veces de Jefe de Gobierno. Si bien es cierto que a lo largo de las últimas décadas han surgido algunos sectores con algún grado de sentimiento republicano, lo real es que nadie hoy se atrevería a cuestionar el gobierno parlamentario. Incluso es más, sometido a referéndum el sistema electoral mayoritario uninominal en 2010, la mayoría de la población se manifestó en contra del cambio para que siguiera todo tal como está. Lo anterior va en directo contraste con lo que ha ocurrido en América Latina, donde la falta de acuerdo político para mantener sistemas estables a lo largo del tiempo han impedido consolidar las instituciones políticas.

En este sentido, Argentina y Chile se han visto cuestionando varias veces el tipo de régimen político y cómo se deben estructurar las composiciones de los órganos políticos institucionales más relevantes. Ambos países hasta finales del siglo XX, e iniciado el actual, han seguido redefiniendo la Constitución, y con ello afectando la conformación de los poderes del Estado, incluyendo la configuración de derechos y deberes, así como cuál es el rol del Estado.

Lo anterior es previo y diferente a la subsistencia del sistema democrático, pues no existe la posibilidad de una regresión autoritaria, siendo la única vía válida la que constituye el recurso electoral y la eliminación de los juegos de doble concurrencia (autoritarismo-democracia) que Kenworthy (1970) viera hace cuatro décadas diseminados por la región. Mientras algunos argumentan un movimiento hacia la izquierda en la región (Panizza, 2009), y otros sostienen que algunos sectores del continente tienen crisis de representación (Mainwaring, 2006), lo cierto es que estos últimos años constituyen un momento particular para generar una cultura democrática que establezca path dependency entre los actores políticos. Por el contrario, nada hace presuponer que la falta de un pacto social en materia de régimen político pudiera derivar en la región a que más quiebres democráticos puedan producirse en el futuro.

1 Agradezco muy sinceramente a los profesores Mireya Dávila y Alejandro Olivares por los comentarios recibidos. Parte de esta aventura historiográfica-política se inició años atrás en el Congreso de la Asociación Británica de Ciencia Política (PSA) en su conferencia de Leeds, abril de 2005. Todos los errores y horrores siguen siendo míos. 
No se trata de cuestionar el presidencialismo como sistema de gobierno, si no que las formas políticas que tomen como régimen político permanezcan en el tiempo, generando tradiciones y respeto en la población.

En este contexto, este trabajo histórico-comparativo analiza por qué pese a que todos los países de América Latina asumieron el presidencialismo, este nunca ha generado en sus efectos un path dependency respecto a sus instituciones, utilizando como caso de estudios la evolución institucional de Argentina y Chile. En estos casos, es posible analizar que los verdaderos sostenedores de la continuidad institucional han sido las élites, y que cuando han fallado, como en el caso argentino desde la década maldita de 1930, simplemente el sistema político ha colapsado. En este contexto, el elemento diferenciador — bajo la lógica comparativa de JS Mill—, ha sido la sobrevivencia de la élite chilena versus el declive de la Argentina.

Los principios de continuidad han sido generados por las élites, devenidos en acuerdos constitucionales en los períodos posteriores a los procesos de Independencia y que han reemplazado acuerdos sociales amplios. Las tensiones entre la élite y el resto de la población han generado distintos equilibrios sub-óptimos, muchas veces muy lejos del mejor posible de alcanzar, con distintas reacciones por parte de los otros segmentos de la población. En este contexto es relevante y necesario preguntarse de dónde salieron los miembros de los gobiernos (incluyendo gabinetes y el congreso), a qué clase social pertenecían. Si bien es cierto que existen análisis cuantitativos sobre el punto, lo cierto es que falta más análisis histórico cualitativo que recoja e interprete la literatura existente.

\section{El Presidencialismo no es producto de Path Dependency en Argentina y Chile}

En la ciencia política latinoamericana ningún otro tema ha recibido más atención que el presidencialismo. Lo extraño es que pese al interés que hay por el régimen político como tal, menos interés ha habido por analizar su origen y quienes han sido los grupos sociales que lo han mantenido. Se ha sostenido por prácticamente toda la literatura académica que este tipo de poder ejecutivo es parte de la historia de América Latina y que no es razonable pensar que pueda cambiar en el futuro. (Foweraker, Landman y Harvey, 2003: 77-79). En este sentido, Cheibub (2002: 104105) argumenta que pese a todas las transformaciones económicas que han ocurrido en el continente durante las últimas décadas, más otros cambios culturales, el 
régimen político se ha mantenido presidencialista, incluso a pesar de la cantidad de autores y políticos que han acusado a dicho modelo de gobernanza como causa y responsable de la inestabilidad, amén de culpable de todos los quiebres democráticos experimentados en la región.

En este mismo sentido, Foweraker (1998) sostuvo que en el futuro de la región de América Latina era muy poco probable que fuese a producirse un cambio en el régimen político, asegurando que frente al tema de las reformas institucionales en el continente, la clase política ha estado haciendo "jardinería" más que realmente estableciendo propuestas de nuevos diseños institucionales para los países. Foweraker sostiene que más que analizar los méritos del presidencialismo en una discusión comparada con otro régimen, como podría ser el sistema parlamentario, resulta mucho más razonable analizar las variantes internas de cada uno de los regímenes, a la vez que no tiene sentido comenzar con análisis normativos de una realidad que no va a cambiar tan drásticamente.

Es así que analizando al interior de este modelo de gobernanza, el presidencialismo en la región fue introducido por todos los padres de la patria en el continente. Siguiendo la terminología de la Constitución de los Estados Unidos ${ }^{2}$, pero tomando en consideración otras razones ${ }^{3}$, los países de América Latina desarrollaron lo que Phillip (2003) ha denominado como Presidencialismo bolivariano, centralizado en la figura de un fuerte liderazgo (Eaton y Samuels, 2003: 24). En este contexto, más que un check and balance, la autoridad tiene un claro incentivo para ejercer el poder casi sin fuerza, en contrario, valiéndose de la burocracia del estado, manteniéndose el sistema como dominante casi sin contrapeso en la región hasta 1982 (Eaton y Samuels, 2003: 24). Más que un Presidente en el estilo creado en Filadelfia, lo que se pretende es una autoridad fuerte que viniera a reemplazar la antigua corona española, más que una autoridad débil sujeta a otros poderes del Estado, y es por eso que existe una clara separación de los poderes, incluyendo el Legislativo y Poder Judicial (Eaton y Samuels, 2002:11). En este contexto, también se entiende la presencia del federalismo, como una forma de dividir el poder en muchas manos en el contexto de un estado nación, considerando el histórico temor que tuvieron los Estados locales de perder sus propias tradiciones históricas de poder frente al gobierno central (McKay, 2001:64).

\footnotetext{
Con la excepción de Brasil que siguió un modelo imperial.

3 Los padres fundadores de Estados Unidos consideraban su máximo temor a la existencia de una tiranía entre ellos, y que pudiera destruir su sociedad. En este sentido, para Madison, el modelo presidencial diseñado es menos permeable a la llegada de dictadores (Eaton y Samuels; 2002:11).
} 
Es a partir de lo anterior, que es posible señalar que en la forma de presidencialismo latinoamericano, más que un contrapeso de poderes, lo que se busca es un carácter fuerte que ejerza su poder de la mano de una burocracia que responde a su mando. Es decir, más que un Presidente, la idea en la región fue buscar un substituto que continuara la lógica del monarca español. Esta idea que ha sido recogida por autores conservadores chilenos como Bernandino Bravo Lira (1986) y otros, es entendida como una necesidad de los constituyentes de la época por tener un poder dominante central más que una institución democrática. En este contexto, y utilizando el ejemplo de Nino (1996:165), sobre el presidencialismo argentino, el resultado fue la idea de un "rey elegido" que es democrático en su origen, pero absolutista en su ejercicio. Este esquema ha fallado en integrar las mayorías que son sub-representadas en la región, e incluso más, al interior de la propia élite no hay una real consciencia cerca de la naturaleza del sistema político que estaría en curso. Más bien, el interés sería defender el orden social a cualquier costo, convencido de la idea aristocrática que la población está muy mal preparada para disfrutar de la democracia. De hecho, la lógica es que la participación política sólo es permisible cuando no existe una amenaza al status quo que fue impuesto top-down.

Por lo tanto, no es posible esgrimir que el presidencialismo no es un tipo de ejecutivo viable para el continente, fundamentalmente porque se ha equivocado en poner ese tema como el principal problema que enfrenta la región. En este sentido, hoy más parece un problema la falta de legitimidad del pacto social existente, el que genera élites poderosas en el poder sin un real acuerdo con el resto de la población para que se sienta parte del sistema institucional. Es decir, las élites, han generado fenómenos de path dependency en virtud del cual han excluido o cooptados, con retornos crecientes de poder, a los grandes sectores sin integrarlos al sistema de toma de decisiones reales.

En este contexto, e independiente de las ventajas que pueda tener uno u otro modelo de gobernanza, parlamentario o presidencialista, lo cierto es que en muchos momentos de la historia el presidencialismo estilo bolivariano establecido en la región, ha generado como efecto que en Argentina y Chile no tomen necesariamente las formas democráticas e inclusivas socialmente para todos los habitantes de dichos países. En este sentido, este trabajo argumenta que dado un contínuo patrón de sistemas políticos centrados en las élites hizo sobrevivir regímenes con déficit democrático en Argentina y Chile. La diferencia se comienza a percibir sólo a mediados del siglo XX, donde en los primeros y producto de la impericia de las élites, estas se abren a las nuevas generaciones de inmigrantes, mientras que los segundos frenan todo reformismo a partir del golpe militar de 1973. En este sentido, la institucionalidad ha 
sido limitada por los golpes de estado que han reemplazado la Constitución en muchos períodos históricos, pero también por élites que han desconocido del estado de derecho en períodos poliárquicos por medio de la imposición de castas, corrupción, clientelismo, entre otros.

\section{La naturaleza del pacto social faltante}

La historia de Argentina y Chile fue construida sin pactos sociales que hicieran de la democracia un retorno creciente. Los procesos de decisión han tenido actores variados en la historia, pero todos han optado por decisiones que se apartan del mejor sub-óptimo posible en términos de institucionalidad jurídico-política, privilegiando intereses de grupos particulares en la sociedad. Esto ha sido la regla desde el fin del colonialismo español, en que las repúblicas que le sucedieron terminaron por repetir las estructuras sociales anteriores, considerando además que fueron los independentismos un movimiento derivado de las altas élites de los países. El presidencialismo por tanto no fue un reemplazo para el status quo.

Los actores políticos en una democracia necesitan reglas claras y cartas no marcadas previamente que privilegien a un grupo determinado. En este sentido, lo relevante es institucionalizar prácticas y no actores específicos. Por lo anterior, lo que ocurrió en el siglo XIX fue establecer la pre-eminencia de un grupo, más que una práctica constitucional, y en donde el aparato del Estado quedó a merced de grupos de interés más que de prácticas. En la literatura sobre la relación con procesos de democratización resulta fundamental asegurar el valor moral y la necesidad primaria de asegurar el estado de derecho (Nino, 1996a:163). En este sentido, también Linz y Stepan (1996) han señalado que para el proceso de consolidación democrática resulta fundamental la existencia de un verdadero estado de derecho, en donde todos los habitantes del territorio se encuentren habituados a la resolución de conflictos dentro de un marco legal o de, procedimientos e instituciones que han sido sancionadas dentro del marco democrático. Es más, los mismos autores sostienen que para lo anterior, es clave que la sociedad alcance importantes niveles de consenso en materia constitucional dentro de la sociedad, para luego generar quórums muy altos para su modificación, con una clara jerarquía de leyes y que sean interpretadas por un poder judicial independiente, con un fuerte sistema legal (Nino, 1996b:10).

Además de la visión presentada, desde una perspectiva práctica Przeworski (1991:14) argumentó que la democratización tiene como paso decisivo que exista la devolución 
del poder de personas a un conjunto de reglas. Por lo tanto, el momento crucial de una verdadera transición del autoritarismo a la democracia es cruzar el umbral desde donde ningún actor tiene la capacidad de intervenir y revertir el resultado de un proceso político formal. Aceptando lo fundamental de la conceptualización que realiza el autor polaco recién mencionado, algunos en la literatura consideran que este queda sólo en la participación electoral y la capacidad de contestarle a la autoridad, mientras el estado de derecho apunta a un espectro mayor que incluye otras libertades públicas como la de prensa, la de asociación y otras que aseguren la posibilidad de todas las personas para ser parte de la cosa pública. Es así que Diamond (2003) argumenta que, a menos que se pongan todos los derechos civiles como igualmente importantes y constitucionalizados, los regímenes se transformarían en democracias iliberales o pseudo-democracias, esto sigue la misma lógica de lo planteado por Zakaria (2003). Por su parte O’Donnell (1993: 1361) refuerza esta línea argumentativa, asegurando que poco valor tiene una democracia donde una persona puede votar libremente y en que su sufragio sea contado de manera justa, pero que a la vez recibe mal trato de la policía o de las Cortes de Justicia, significando que la ciudadanía como concepto está coartado. El daño puede afectar los cimientos del sistema de una democracia liberal, y afectar la sobrevivencia de las fundaciones mismas de la institucionalidad (Unger, 2002: 234).

La Constitución es la base legal de la expresión formal de la ciudadanía, que se hace viva más allá de un proceso electoral. En este aspecto, el acuerdo no es artificial o accidental, si no que el fruto de una contínua interpretación dada a lo largo de la historia de la nación, la que es definida como Constitución Histórica (Nino, 1996b: 15). Es esta convención social donde todos los actores envueltos continúan a lo largo de las generaciones construyendo el concepto de lo que el texto significa para la población (Nino,1996b:33). Lo anterior, significa que la norma sólo debe ser preservada si se someten a la evaluación de la población, incluyendo las nociones de derechos individuales y la democracia que son valores superiores (Nino, 1996b:42). Es decir, el principio de constitucionalismo es la base de apoyo para el estado de derecho, lo que de acuerdo a Foweraker, Landman y Harvey (2003:77) va mucho más allá de las pasiones y eventos de la historia, con la provisión de una estructura legal para el funcionamiento del gobierno que sea lo suficientemente estable para que trascienda el paso del tiempo.

En el contexto de lo discutido hasta ahora, resultan interesantes las ideas presentadas por Bresser Pereira y Nakano (1998) con respecto a la falta de un contrato social como factor explicativo para la falta de gobernabilidad. Para los autores brasileños, la legitimidad del gobierno y las reformas económicas dependen de un mínimo acuerdo 
social básico que en la región de América Latina no existe. La ausencia de ese pacto, es en parte dado por los bajos niveles de participación en la sociedad civil, combinado con políticas económicas neoclásicas que conceptualizan al Estado como un factor exógeno al desarrollo. En este aspecto, para cambiar la realidad, es necesario al menos un pacto orientado al desarrollo entre las principales fuerzas políticas.

Bajo la perspectiva institucionalista de la economía, el mercado es considerado como una institución informal reglada por la gente, y sólo de manera formal por el Estado, significando que los individuos son agentes de mercado pero también agregadores de interés a través de la sociedad civil y del Estado (Bresser Pereira y Nakano, 1998:25). Consecuentemente, aunque la política y la economía formalmente pertenecen a dos ámbitos diferentes, el Estado es en realidad un factor endógeno del sistema económico, y una crisis en uno lleva a la crisis en el otro, y viceversa (Bresser Pereira y Nakano, 1998: 26).

Considerando lo expuesto, existe un área gris que requiere un contrato social que llene el vacío. Para Bresser Pereira y Nakano, este pacto es esencial para las sociedades capitalistas, donde más allá del trade-off entre el orden y la libertad, el Estado puede actuar como un tercer actor que es un intermediario efectivo. La presencia de este pacto asegura que sean mejores los sub-óptimos como productos de negociaciones, pero a la vez poder construir sistemas económicos efectivos y dar legitimidad a gobiernos, con políticas económicas que den cuenta realmente de las necesidades de los ciudadanos (Bresser Pereira y Nakano, 1998:37).

\section{La experiencia de Argentina y el desarrollo institucional chileno}

Asumiendo la lógica presentada hasta el momento, Argentina y Chile hicieron decisiones sub-óptimas o "segundas mejores opciones" como la base de su pacto social institucional, muchas veces incluso lejos de la segunda opción. Según los autores, los acuerdos más avanzados expuestos en el continente son sólo orientados al a desarrollo de pactos políticos, definidos como "coaliciones amplias y de clase que tienden formarse para legitimar un conjunto de interpretaciones y estrategias adoptadas por la élite política que pueden estar representadas y unidas por un partido político, un grupo de partidos políticos asociados, o incluso un grupo de partidos políticos rivales que comparten creencias comunes" (Bresser Pereira y Nakano, 1998: 38). El caso de América Latina muestra cómo incluso estos acuerdos sustitutivos han excluido a amplios sectores de la sociedad, tales 
como los procesos nacionalistas en los años 50 (Bresser Pereira y Nakano, 1998: 38). Por otra parte, los autores subrayan que esos pactos hoy están ausentes, lo que significa que los actuales gobiernos democráticos enfrenten una permanente crisis de gobernabilidad (Bresser Pereira y Nakano, 1998: 39), y que las reformas económicas no dependan sólo de consideraciones institucionales o personales, sino que esencialmente de un acuerdo básico sobre la organización económica y el sistema político.

El marco de análisis de Bresser Pereira y Nakano tal vez exagera la relevancia de la economía como un factor para el logro de la gobernabilidad. Sin embargo es parte integrante del argumento central, afirmando que para la supervivencia de la democracia y su estabilidad, es clave que no hayan grupos alejados de la mesa de negociación constitucional. Incluso la economía tiene que seguir los principios jurídicos por los que una sociedad se mantiene, y, en consecuencia, nadie puede ser restringido por ser capaz de acordar o proponer cambios cuando sea adecuado. Teniendo en cuenta la preeminencia de las élites en las políticas de toma de decisiones en ambos casos, no está claro por qué fracasan los planes económicos, pero está claro cómo el país en su conjunto no logra mantener previsibilidad de sistemas democráticos fiables.

Con lo anterior en consideración, se pretende explicar por qué la falta de acuerdo constitucional ha sido posible a nivel individual y agregado, y también destaca la brecha entre países desarrollados y subdesarrollados en relación directa con el ausente pacto social, que se refiere, a nuestro juicio, a la falta de una forzada constitución democrática. En consecuencia, este análisis comparativo contrasta con los estudios de los países desarrollados, como ejemplos de éxito global como la Constitución Americana de 1787, que había impuesto un marco federal presidencialista no esencialmente desafiado por los acontecimientos. De hecho, las modificaciones existentes no están relacionadas con el cambio de los principios básicos del sistema en cuestión (McKay, 2003:52-58).

Dentro de este contexto, es posible analizar por qué en el siglo XIX, en Argentina y Chile se privilegió el orden interno como el logro más valioso, sobre todo, después de sufrir la incertidumbre derivada del complejo proceso de la organización nacional. En ambos casos, como en toda la región, el conservadurismo social y político prevaleció porque la élite temía la pérdida de privilegios y desconfiaba del cambio. Sin embargo, el continente no siguió un modelo uniforme de desarrollo político, e incluso los métodos y procedimientos conllevaron distintos caminos en disímiles contextos. Con respecto a este tema, Cavarozzi (1992:235) distingue tres vías políticas adoptadas por los países de América Latina durante el siglo de emancipación: 
- Supremacía Imbatible de la Élite: adoptadas por los países en los que el poder político y económico fue descentralizado en las diferentes regiones de su territorio, como Colombia, Brasil y México pre 1911.

- El Caudillismo militar y la inestabilidad política: el resto de la Región Andina y Centroamérica (con la excepción de Costa Rica).

- Gobierno Oligárquico Constitucional: implica la inducción de la modernización política de control sobre la expansión de la participación. Estos fueron los casos de Argentina, Chile, Uruguay y Costa Rica unos años después.

Como se puede observar, Argentina y Chile comparten un punto común de partida basado en las ideas del constitucionalismo oligárquico. Siguiendo la clasificación de Cavarozzi, el primer momento crítico ocurre cuando las élites nacionales aceptaron el resultado de las inestabilidades posteriores a la independencia. Este es el caso de la Constitución Chilena de 1833 como un asentamiento de disputas conservadores/ liberales, mientras que en Argentina la Constitución de 1853, modificada en 1860, devuelve el poder a Buenos Aires, terminando décadas de enfrentamientos centro/ periferia. Por lo tanto, vale la pena reflexionar sobre la base de la construcción del acuerdo constitucional, que permite a un Estado existir y desarrollarse. Utilizando la clasificación de Negretto (1998:3), hay tres elementos principales que definen el resultado de cualquier proceso de construcción de una Constitución democrática:

- El inicio del proceso de construcción de constitución supone la existencia de una cierta cantidad de actores que quieran crear nuevas reglas sobre la distribución y el ejercicio del poder político en la comunidad.

- Este proceso tiene lugar en un contexto político dividido por grupos con puntos de vista diferentes y conflictivos acerca de cómo sus intereses y valores pueden ser mejor realizados a través de diferentes instituciones.

- La Constitución no puede ser creada a menos que todos los actores o una mayoría importante de ellos encuentra una manera de resolver sus diferencias.

Chile no cumplió ninguno de estos criterios, teniendo en cuenta que al menos la primera Constitución perdurable fue la de 1833, cuyo texto es el resultado de una imposición autoritaria hecha por los conservadores pelucones. Fue la facción ganadora de la guerra civil sobre los pipiolos liberales, posible en parte como reflejo de la creciente insatisfacción entre los comerciantes y hacendados que estaban cansados del desorden y el conflicto (Gil, 1965:86). Para los conservadores, el objetivo 
era basar su autoridad en "la evolución de las instituciones jurídicas de la joven república y en armonía con las estructuras sociales, básicamente sin cambios de régimen rural antiguo. Durante este período, el prestigio social y el poder político continuaron siendo muy vinculados a la posesión de la tierra" (Scully, 1992:23-24). Por lo tanto, se estableció un sistema en el que el voto fue censitario (condicionado), con más limitaciones para aquellos interesados en postularse para un cargo público. En este sentido, la Constitución declaraba en el fondo la existencia de dos tipos de ciudadanos: los elegibles para ejercer los derechos ciudadanos y los inhabilitados.

Así, la Constitución representa a los intereses de la oligarquía para preservar el sistema social, la imposición de un sentido de orden y jerarquía del Estado, amén de una clara cadena de mando de las Fuerzas Armadas. Diego Portales, como padre fundador institucional (aunque en realidad sólo fue inspirador de la Constitución), desconfiaba seriamente cualquier creencia en el buen juicio de las mayorías, y al contrario, sólo " $\mathrm{el}$ peso de la noche" entregará ciudadanos virtuosos que con el tiempo serán suficientemente capaces para hacer funcionar su propio negocio (Jocelyn-Holt, 1997:145-177). De hecho, a través de sus escritos, es posible aclarar su malestar con la democracia:

"La democracia, que tanto pregonan los ilusos, es un absurdo en los países como los americanos, llenos de vicios y donde los ciudadanos carecen de toda virtud, como es necesario para establecer una verdadera República. La Monarquía no es tampoco el ideal americano: salimos de una terrible para volver a otra y ¿qué ganamos? La República es el sistema que hay que adoptar; ¿pero sabe como yo la entiendo para estos países? Un gobierno fuerte, centralizador; $\mathrm{cu}-$ yos hombres sean modelos de virtud y patriotismo, y así enderezar a los ciudadanos por el camino del orden y de las virtudes. Cuando se hayan moralizado, venga el gobierno completamente liberal, libre y lleno de ideales, donde tengan parte todos los ciudadanos. Esto es lo que yo pienso y todo hombre de mediano criterio pensará igual" (Carta de Diego Portales a José M. Cea, 05/03/1822).

Los valores de Portales (impuestos por otros en su nombre), se reflejan en toda la construcción de la identidad del Estado nacional. Durante los siguientes cuarenta años, será la república autoritaria, generando retornos crecientes de las formas republicanas basadas en el imperio de la ley, a pesar de que las normas se establecen por unos pocos y no por la mayoría de la gente. Como se afirmó, las condiciones establecidas en las conclusiones de Negretto están lejos de la realidad histórica de Chile, 
y por lo tanto, no es democrático en el origen y el ejercicio. En la construcción de los ideales portalianos o conservadores, el sistema fue ayudado por una particular élite; ya mezclada racialmente, con una aristocracia y burguesía que rápidamente se fusionaron en un solo grupo (Gil, 1965:28).

Por otro lado Scully (1992), establece una fisura generativa en la ruptura del modelo español autoritario hacia mitad del siglo XIX, creado por el nivel de intervención del Estado en el clero, que divide las élites entre elementos liberales y conservadores, lo que permite la creación de un verdadero sistema de partidos en 1861. Sin duda, fue importante en la creación de un marco para los modernos partidos políticos, pero produce pocos cambios en la participación democrática y la inclusión al sistema. De hecho, el principal cambio resultante del fin de la era conservadora o autoritaria es que para 1870 la élite no estaba uniformemente siguiendo los patrones conservadores de Portales, a pesar de que nadie dentro de los círculos de poder propusiera alguna vez incluir a otros sectores sociales en la esfera política.

Posteriormente, el primer líder político que abordó la necesidad de modernizar la política fue el Presidente José Manuel Balmaceda, sin embargo su lucha terminó en una guerra civil. En perspectiva histórica, el renombrado historiador marxista chileno Ramírez Necochea (1958: 175-176) retrata la imagen del Gobierno de Balmaceda como la búsqueda de una agenda liberal, utilizando como prueba las reformas constitucionales para establecer el sufragio universal masculino, promoviendo a la vez reformas municipales para mejorar los niveles de participación local, y además, en las elecciones generales limpias en comparación con los procesos tradicionales fraudulentos del tiempo. La élite atrincherada en el Congreso provocó una guerra civil y Balmaceda perdió su gobierno y la vida. Las secuelas representaron que la mayoría de la élite terminara apoyando un régimen pseudo-parlamentario, que al final no era nada más que un desorden profundo de rotativa ministerial y muy poco del orden parlamentario europeo. Como sostiene Reinsch (1909), más parecía un club de amigos y al parlamento inglés del siglo XVIII que a un moderno Congreso Nacional. Al final, el resultado de la guerra civil de 1891 representó el éxito de la defensa corporativa de los partidos parlamentarios de la élite, y contrariamente a la creencia de muchos historiadores chilenos, este período no representa una situación crítica con un legado de cambio.

Siguiendo esta línea de argumentación, es posible llegar a acuerdo con Scully (1992:63) cuando argumenta que la candidatura de Alessandri a la presidencia en 1920 marcó el comienzo de un período de profundo cambio institucional que se prolongaría hasta 1932. Por otra parte, era la posibilidad para los sectores no-élite 
para ser realmente contados como parte del universo electoral, compartir ciertas cuotas de poder, e incluso llegar a la presidencia del país. El Frente Popular (FP) ganador de 1938 demostró cómo el a la izquierda o partidos obreros fueron capaces de obtener el poder electoral y realmente se les fueran concedidos derechos políticos. También se demuestra cómo la izquierda abrazó procedimientos democráticos y estrategias electorales para buscar el poder, hasta llegar a la Presidencia en 1970 (Taylor, 1998:32). Esta es también una decisión sub-óptima, donde se pospusieron sus ideales revolucionarios de transformación social con el fin de alcanzar gradualmente el éxito, una tendencia no eliminada incluso para luchar contra la dictadura de Pinochet y la posterior transición, como se muestra en la tabla 1:

Tabla 1

Evolución de las decisiones sub-óptimas de la Élite y reacciones sociales en Chile

\begin{tabular}{|l|c|}
\hline \multicolumn{1}{|c|}{$\begin{array}{c}\text { Decisiones sub-óptimas de la Élite } \\
\text { (restauración de élite) }\end{array}$} & Reacción de la No Élite \\
\hline $\begin{array}{l}\text { Constitución de 1833 } \\
\text { Estado Portaliano }\end{array}$ & 1920 Elección Arturo Alessandri \\
\hline $\begin{array}{l}\text { Constitución Presidencialista de 1925 } \\
\text { Participación limitada de las personas }\end{array}$ & $\begin{array}{c}\text { 1938-1973 Compromiso democrático de la } \\
\text { izquierda, reformismo }\end{array}$ \\
\hline 1973-1990 Dictadura militar & 1989-2000 Transición pactada \\
\hline
\end{tabular}

Fuente: Construcción propia

La élite no permitiría la participación que pusiera en peligro su preeminencia. Dos momentos históricos pueden probar el caso, la prohibición del Partido Comunista en 1949, conocida como Ley Maldita, con una masiva represión contra izquierdistas y líderes sindicales, y después, el burocrático-autoritario régimen post-1973. El proceso de democratización tras la derrota del dictador Augusto Pinochet en el plebiscito de 1988, representó la posibilidad de reformulación de las principales características antidemocráticas de la Constitución de 1980. A través de la negociación y el referéndum constitucional de 1989, una forma implícita de transición pactada fue sellada, creando las condiciones suficientes para la democracia, a pesar de que la consolidación estaba lejos de ser una realidad (Godoy, 1999:83). Hasta hoy, los chilenos discuten la manera de garantizar la voluntad popular en un injusto, y poco competitivo, sistema electoral pro-élite.

En Argentina, el país nunca reunió tampoco las condiciones que presenta Negretto. Sólo después de décadas de gobierno autoritario fue posible promulgar una Constitución. Cuando el dictador Juan Manuel de Rosas fue expulsado del poder en 1852, 
había una sensación de veinte años de desarrollo institucional congelado (Lorenzo, 1994:184). Por lo tanto, la élite política entendió la relevancia de una Constitución nacional que pudiera organizar al Estado bajo el mandato de la Ley (Lorenzo, 1994:197). Para este propósito, se celebró una convención federal en Santa Fe para entregar el texto, que fue muy influenciado por la figura y la obra de Juan Bautista Alberdi. Mucho se ha escrito sobre el peso del modelo de EE.UU. en la escritura de la Constitución original argentina de 1853, aunque el autor lo negó siempre. Públicamente, él reconoce su admiración por el modelo de Madison, pero sostiene que el enfoque de federalismo era más debido a sus estudios de autores como Tocqueville en lugar de su intención de copiar el modelo estadounidense (Pérez Guilhou, 1994: 64). De hecho, al examinar el modelo de presidencialismo buscado por Alberdi, la ruta creada por el modelo chileno de 1833 inmediatamente es encontrada:

"El tiempo ha demostrado que la solución de Chile es la única racional en repúblicas que poco antes fueron monarquías. Chile ha hecho ver que entre la falta absoluta de gobierno y el gobierno dictatorial hay un gobierno regular posible; y es el de un Presidente constitucional que pueda asumir las facultades de un rey en el instante que la anarquía le desobedece como presidente republicano" (Alberdi, 1960:115).

Esto culmina un proceso en el cual Argentina ha estado en la búsqueda de unificar los poderes en uno solo.Veinte años antes de la Constitución, la principal preocupación de Rozas como líder de la Provincia de Buenos Aires era asegurar un gobierno unificado bajo su mando autoritario, básicamente, con el fin de proteger los intereses de las élites agrarias locales y regionales. Por otra parte, su visión de la situación se asemejaba a la estancia, donde la sociedad está construida imitando a escala nacional la relación patrón-peón (maestro-esclavo) (Lynch: 1993:26). Por lo tanto, el híper presidencialismo consagrado por la Constitución es en cierto modo el legado político de Rozas, a pesar del hecho de que los redactores convencionales fueron sus oponentes más fuertes. Como se muestra en el Tabla 2, esta fue la base de una tensión continua entre la élite y el pueblo, pero también, con aquellos interesados en la liberalización de ganar poder sobre los seguidores de la heredada trayectoria de dependencia. 
Tabla 2

Evolución de las decisiones sub-óptima de Élite y reacciones sociales en Argentina

\begin{tabular}{|l|c|}
\hline $\begin{array}{l}\text { Decisiones sub-óptimas de la Élite } \\
\text { (restauración de élite) }\end{array}$ & Reacción de la No Élite \\
\hline 1853 Constitución de Alberdi & $1916-1930$ Compromiso reformista de la UCR \\
\hline $1930-1943$ Restauración Conservadora & $1945-1955$ Proyecto peronista populista \\
\hline $1955-1983$ "Juego Imposible” & 1983 Comité Democrático \\
\hline $\begin{array}{l}\text { 1994 Pacto de Olivos } \\
\text { Cuasi Parlamentarismo }\end{array}$ & $\begin{array}{c}\text { 2001 Qué se vayan todos!!! Los disturbios y } \\
\text { crisis Presidencialista }\end{array}$ \\
\hline
\end{tabular}

Fuente: Construcción propia

Después de la discusión centro-periferia, se resolvió en 1863 que la capital volviera a Buenos Aires. Representó el final de años con guerras civiles, y la tarea nacional de unir a un estado extremadamente diverso bajo la idea de una nación. Esta fue la principal preocupación de los que ahora se conocen como la "Generación de 1880", unificados a través del Partido Autonomista Nacional (PAN). Centrados sobre todo en la riqueza y la inversión extranjera en el país, la principal prioridad de este partido político era la preservación de élite. Como Rock (1974:25) señaló: "La política entre 1880 y la Primera Guerra Mundial son inteligibles en términos de compromiso de la élite a la preservación de la estabilidad y el crecimiento".

Para lograr esta meta, el fraude era la mejor opción, permitiendo la mantención y defensa del mito de las libertades constitucionales, mientras que en realidad había mucho más intimidación. Contra esta imposición, sólo las clases medias podrían obtener algo. La Unión Cívica Radical (UCR), se organizó políticamente por los ciudadanos privados de sus derechos pero debido al compromiso de la violencia en las primeras etapas, su acceso al poder fue disminuido severamente.

Aún así, la lucha tuvo cierto éxito después de la ley Sáenz Peña de 1912. A través de esta reforma electoral, todos los ciudadanos varones tenían asegurado el derecho a votar en una elección limpia, con una clara lista de los votantes registrados. Además, la enmienda incluía que la educación se convertiría en laica, obligatoria y gratuita, (Di Tella, 1999:140) Sin embargo, esto no es un punto de inflexión o una coyuntura crítica que revela un cambio en la política argentina, por el contrario, sólo se reconoce un problema: que para la élite era menos costoso aceptar ciertos niveles de participación, o incluso dar la presidencia a las clases medias, en lugar de perder 
todas las prerrogativas sociales y económicas adoptadas por sentado después de un siglo de la Independencia, muy en la lógica de cuándo los actores políticos aceptan las transiciones desde una perspectiva racional (Colomer, 2001).

Más tarde, en 1916 con la UCR ganando la presidencia, la primera coyuntura crítica de verdad ocurrió, dando forma al compromiso de las clases medias. Sin embargo, el alcance del cambio y la transformación fue limitada, principalmente porque los dirigentes no entendían la importancia de la reforma agraria o la necesidad de verdaderas mejoras sociales. Ellos nunca promovieron la industrialización del país y de grupos relacionados con los propietarios de tierras, reteniendo demasiado poder dentro del partido (Rock, 1975:271). Sin embargo, este es un momento crítico importante porque muestra la capacidad de la parte media y algunos dentro de la clase trabajadora para acceder al poder, así como la aptitud del país para integrar a los inmigrantes y otros grupos sociales excluidos. Se construye la identidad de una posición democrática, y probablemente, una de las pocas ocasiones en la historia donde el estado de derecho ha sido pre-eminente.

A pesar de lo poco revolucionario que fue el programa de gobierno de la UCR, este fue considerado demasiado extremo para los conservadores, quienes inauguraron las prácticas modernas de golpes de Estado contra gobiernos legítimos, con un triste legado que continuó hasta la Junta de Facto que gobernó entre 1976 y 1983, y que entre otras barbaridades llevó al desastre de Las Malvinas. A su vez, los conservadores repitieron las prácticas de fraude y cohecho que practicaban previos a las reformas electorales de 1912.

Lo anterior fue el caso de las elecciones para gobernador de Buenos Aires en 1931, conocidas por ser fraudulentas, las que habrían sido efectivamente ganadas por el radical Honorio Pueyrredón. Sin embargo, el gobierno anuló la elección sin ninguna razón plausible (Romero, 2002:59). Esto representó la restitución del llamado fraude patriótico todos los niveles electorales, y más importante aún, como un momento crítico que representa la falta de compromiso de la élite con las reformas democráticas.

Más tarde, la Segunda Guerra Mundial y la influencia de una tradición no democrática ni liberal para el ejercicio electoral, trajo la decadencia política a un país donde la herencia de la crítica conservadora coyuntura tan profundamente faltando el respeto al estado de derecho. La élite no entendió la naturaleza cambiante de la política moderna y cayó por sus propios errores a un nuevo tipo de personaje. Juan Domingo Perón representaba las aspiraciones de millones de carenciados dentro de la población. Era la voz de aquellos en la clase obrera que por primera vez pudieron 
tener algo que decir. Este es el momento crítico más relevante, por lo que la no-élite decidió seguir a un líder y no un conjunto de reglas, un movimiento y no necesariamente un partido, y más importante, utilizar todos los medios para luchar contra la injusticia, como tan vívidamente retrata McGuire:

"El objetivo del movimiento es poner un peronista que promulgue políticas de conformidad con la justicia social, la independencia económica y la soberanía nacional. Este objetivo se puede lograr por parte mediada por la participación electoral, así también como con una alianza con oficiales militares simpatizantes o por una huelga general insurreccional. El líder plebiscitario y el sindicato, y no la organización del partido, han sido siempre el núcleo, realizaciones indispensables del peronismo" (McGuire, 1997:1).

Como es evidente, la democracia liberal se convierte en poco interesante porque no había ninguna recompensa política. Las clases populares decidieron tomar otros caminos para defender sus alienados derechos políticos. Por lo tanto, la diferencia de resultado principal entre los dos países no está representado en el nivel compromiso con el estado de ley, sino que más bien reside en el compromiso con los valores democráticos, los movimientos populares chilenos, siempre valoraron la democracia en comparación con sus contrapartes argentinos, donde la democracia era sólo una de varias herramientas posibles. De hecho, Perón nunca dudó ya sea para frenar las libertades políticas o excluir a la oposición de cualquier forma real de representación. Esta diferencia es actualmente esencial para explicar los niveles de estabilidad, a pesar de la falta de acuerdo constitucional en Chile, y el permanente estado de crisis experimentado por Argentina, especialmente en el período post-Menem.

El final de la década peronista, en 1955, es en sí mismo uno de los puntos críticos más relevantes. Las Fuerzas Armadas y el comportamiento de los grupos antiperonistas resultaron en lo que O’Donnell (1979:130) había descrito como una “drástica disminución en la participación del ingreso salarial en el Producto Nacional Bruto, numerosos intentos de debilitar los sindicatos y la proscripción electoral del peronismo". Lo anterior disminuyó las perspectivas de éxito en la democracia en Argentina y estableció el juego imposible de competencia del sistema de partidos en el país, en donde ningún competidor realmente podría tener alguna posibilidad de ganar si no competía en contra del peronismo, haciendo a cualquiera sospechoso de traición bajo los ojos del juez militar (O’Donnell, 1979:174). De hecho, esto representaba una clara forma de 
segregación social en toda la nación. Las fuerzas sociales y sindicales estaban verdaderamente con el peronismo, y llegaron a ser completamente excluidas de cualquier forma de representación (Cavarozzi, 2003:13).

Como consecuencia de ello, entre 1928 y 1999 Argentina no tuvo ningún Presidente civil al que se le entregó el mando de la nación por parte de un predecesor de la misma condición, y con el mandato completamente cumplido (Alfonsín casi lo logra en 1989, pero una crisis económica lo obligó a realizar elecciones seis meses antes de terminar su período).

Por otra parte, sólo tres periodos anteriores a la última Junta Militar satisfacieron el mínimo de la definición procedimental de democracia poliárquica. Estos fueron los casos entre 1916-1930, 1946-1955 y 1973-1976, sin embargo se puede levantar dudas sobre el último período debido principalmente a la violencia y represión de los derechos políticos (Abal Medina y Suárez Cao, 2002:165). El régimen militar que comenzó en 1976 (como aquel entre 1966 y 1972) ha sido ampliamente analizado, pero derivó en lo destacable del compromiso actual de la sociedad argentina con la democracia electoral, como consecuencia de un trauma doloroso. Es el resultado más positivo después de la dura experiencia, después de que el ejército fuera totalmente aislado como un factor de poder. Incluso en medio de la crisis de 2001, ningún actor relevante pensaba en ellos como una posible salida.

Sin embargo, este compromiso crítico continúa hoy en día, es la misma élite política que retorna al poder con la inauguración de la democracia. El sistema de partidos fue edificado nuevamente sobre la base de los proyectos hegemónicos de los peronistas y radicales en la que cada uno sentía que iban a ser el único movimiento nacional y un mecanismo central en un sistema basado en la soberanía popular (Cavarozzi, 1992: 228). La crisis de 2001 ha puesto de manifiesto una vez más la fragilidad en la que se ha construido el sistema, y probablemente el pacto de la élite de 1994 para reformar la constitución salvó la democracia a través de la introducción de reformas cuasi-parlamentarias (Schamis, 2002), pero que culmina un proceso que carga con la promesa incumplida de la inclusión social de todas las fuerzas políticas. Como subraya Ondetti (1995:115-116), esta es la «culminación de un proceso de negociación extra-institucional entre dos caudillos que buscan principalmente, si no exclusivamente, tal vez, la ventaja política". 


\section{Conclusiones}

Teniendo presente el panorama de ambos países, son más evidentes las diferencias en los resultados, los que se incrementaron durante el siglo 20. En Chile, los partidos de izquierda decidieron mantenerse dentro del proceso político, mientras que en Argentina, la democracia ha sido interrumpida varias veces, cayendo en el compromiso de los actores en el proceso político. Sin embargo, este resultado diferente no ha salvado a Chile de caer en uno de los regímenes dictatoriales militares más terribles en la historia de América Latina, pero sí ayudó a forzar a todos los actores para actuar dentro del sistema con el fin de tener una transición segura a la democracia y para seguir consolidando el proceso, a pesar de los evidentes problemas que enfrento el país.

Como un hecho, después de los últimos procesos de democratización en Argentina y Chile, los resultados del funcionamiento del sistema político y la supervivencia siguen pareciendo diferentes dentro de las actuales disposiciones institucionales, la estructura del partido y el apoyo institucional popular. Como se ha explicado, ellos alcanzaron su situación actual después de una larga historia llena de acontecimientos, que pueden ayudar a explicar dos líneas centrales de la respuesta buscada. En primer lugar, ¿por qué es posible tener colapsos en la democracia? En segundo lugar, y lo más importante, cómo estos acontecimientos históricos afectan a la actual situación política, condicionando el conjunto de opciones institucionales disponibles en un futuro próximo, y por otra parte, los patrones de votación de la población, los registros del Congreso y la línea política del gobierno. En suma, hay unos puntos comunes de salida y la evolución de las decisiones sub-óptimas en la construcción de la dependencia de la trayectoria, y, además, los resultados han variado debido a los diferentes grados de decisiones subóptimas de la no-élite con respecto a la democracia. Sin embargo, también podemos concluir que el orden institucional establecido sigue siendo substituto de un acuerdo constitucional que cambie realmente la cara de ambos países.

En definitiva el orden chileno sólo se sostiene con una élite que opera como jugadora con veto. En Argentina, los problemas de crisis permanente sólo se solucionan si todos los sectores están involucrados en el proceso político, más allá del grupo de turno que siempre quiere reinventar todo de nuevo. Siendo tan diferentes en su recorrido institucional, ambos carecen de un problema de origen en la falta de pacto social. Quizás uno de los problemas que tiene un trabajo que involucra análisis histórico sobre tan prolongados períodos de tiempo es que se pierde detalle. Sin embargo, la pretensión de esta investigación es demostrar mecanismos causales que han sobrevivido en el tiempo y que necesitan urgente revisión. 


\section{Referencias Bibliográficas}

Abal Medina, Juan Manuel y Julieta Suárez Cao (2002). "La competencia partidaria en la Argentina: sus implicancias sobre el régimen democrático”. En Cavarozzi, Marcelo y Juan Abal Medina (compiladores). El asedio a la política: los partidos latinoamericanos en la era neoliberal. Buenos Aires: Konrad Adenauer.

Bravo Lira, Bernardino (1986). El Presidente en la Historia de Chile. Santiago: Editorial Universitaria.

Bresser Pereira, Luiz y Yoshiaki Nakano, (1998). "The missing social contract: governability and reform in Latin America”. En Ducatenzeiler, Graciela y Oxhorn, Phillip. What Kind of Democracy? What kind of Market? Latin America in the Age of Neo-liberalism. Pennsylvania State University Press.

Cavarozzi, Marcelo (1992). "Patterns of élite negotiation and confrontation in Argentina and Chile”. En Higley, John y Gunther, Richard. Elites and Democratic Consolidation in Latin America and Southern Europe. New York: Cambridge University Press.

Cavarozzi, Marcelo (2003). Autoritarismo y Democracia. Buenos Aires: Ediciones Universidad de Buenos Aires.

Cheibub, Jose (2002). "Presidentialism and Democratic Performance". En Reynolds, Andrew. The architecture of democracy: constitutional design, conflict management, and democracy. Oxford: Oxford University Press.

Collier, Ruth y David Collier (1991). Shaping the political arena: critical junctures, the labor movement, and regime dynamics in Latin America. Princeton: Princeton University Press.

Colomer, Josep (2001). Disequilibrium Institutions and Pluralist Democracy. Journal of Theoretical, $\mathrm{N}^{\mathrm{o}} 13$, Vol. 3, pp. 235-248.

Diamond, Larry (2003). Defining and Developing Democracy. In Dahl, Robert; Shapiro, Ian y Cheiub, José. The Democracy Sourcebook. Boston: MIT Press.

Di Tella, Torcuato (1999). Historia social de la Argentina Contemporánea. Buenos Aires: Editorial Troquel.

Eaton, Kent y David Samuels (2002). Presidentialism and, or, and versus parliamentarism: The state of the Literature and an Agenda for future research. Paper presented at the Conference on Consequences of Political Institutions in Democracy. Duke University, April 5-7.

Foweraker, Joe (1998). "Review article: Institutional design, party systems and governabilitydifferentiating the Presidential Regimes of Latin America". British Journal of Political Science, $\mathrm{N}^{\circ} 28$. 
Gil, Federico (1965). The Political System of Chile. Boston: Houghton Mifflin Company.

Godoy, Óscar (1999). "La Transición Chilena a la Democracia: Pactada”. Revista de Estudios Públicos $\mathrm{N}^{\mathrm{o}} 74$.

Hausner, Jerzy; Jessop, Bob; Nielsen, Klaus (1995). Strategic choice and path-dependency in post socialism: Institutional dynamics in the transformation process. Brookfield: E. Elgar Press.

Jocelyn-Holt Letelier, Alfredo (1997). El Peso de la Noche: Nuestra Frágil Fortaleza Histórica. Buenos Aires: Ariel Ediciones.

Linz, Juan y Alfred Stepan (1996). Problems of Democratic Transition and Consolidation: Southern Europe, South America, and Post-Communist Europe. Baltimore: The Johns Hopkins University Press.

Lipset, Seymour y Stein Rokkan (1967). Cleavage Structures, Party Systems, and voter Alignments. An introduction. Lipset, Seymour y Rokkan, Stein. Party systems and voter alignments: cross-national perspectives. New York: Free Press.

Lynch, John (1993). From Independence to National Organization.In Bethell, Leslie. Argentina since Independence. New York: Cambridge University Press.

Lorenzo, Celso Ramón (1994). Manual de Historia Constitucional Argentina Vol. 2 Rosario: Editorial Juris.

Mahoney, James (2000). "Path Dependency in historical sociology". Theory and Society $\mathrm{N}^{\circ}$ 29 pp. 507-548.

Mainwaring, Scott (2006). "The Crisis of Representation in the Andes". Journal of Democracy, Vol. 17, No 3, pp. 13-27.

McGuire, James W. (1997). Peronism without Peron: Unions, parties, and democracy inArgentina. Stanford: Stanford University Press.

McKay, David (2003). American Politics E Society. London: Blackwell Publishing.

Negretto, Gabriel (1999). "Constitution-making and Institutional Design:The Transformation of Presidentialism in Argentina”. Archives Européennes de Sociologie Vol. XL N² 2.

Nino, Carlos (1996). The Constitution of Deliberative Democracy. New Heaven:Yale University Press.

Nino, Carlos (1996). "Hyperpresidentialism and Constitutional Reform in Argentina”. En Lijphart, Arend y Waisman, Carlos H. Institutional Design in new democracies. Boulder: Westview Press.

North, Douglass (1990). Institutions, Institutional Change and Economic Performance. New York: Cambridge University Press. 
O'Donnell, Guillermo (1979). Modernization and bureaucratic-authoritarianism: studies in South American politics. Berkeley: Institute of International Studies, University of California.

Ondetti A., Gabriel (1995). The Politics of Constitutional Reform in Argentina: A Study of the Pact of Olivos. Thesis submitted to obtain the M.A. in Latin American Studies. Washington D.C.: Georgetown University.

Panizza, Francisco (2009). Contemporary Latin America: development and democracy beyond the Washington Consensus. London: Zed Books.

Pérez Guilhou, Dardo (1994). Historia de la Originalidad de la Constitución Argentina. Mendoza: Instituto Argentino de Estudios Constitucionales y Políticos.

Pierson, Paul (2003). Big, Slow-moving: Macrosocial processes in the study of Comparative Politics. En Mahoney, James y Rueschemeyer, Dietrich; Comparative historical analysis in the Social Sciences. New York: Cambridge University Press.

Pierson, Paul (2004). Politics in Time: History, Institutions, and Social Analysis. Princeton: Princeton University Press.

Pierson, Paul y Theda Skocpol (2002). "Historical Institutionalism in Contemporary Political Science”. En Katznelson, Ira y Helen Milner (editores) Political Science: The State of the Discipline. New York: Norton.

Phillip, George (2003). Democracy in Latin America. Polity Press.

Pzreworski, Adam (1991). Democracy and the Market: Political and Economic reforms in Eastern Europe and Latin America. New York: Cambridge University Press.

Ramírez Necochea, Hernán (1969). Balmaceda y la contrarrevolución de 1891 Santiago: Editorial Universitaria.

Reinsch, Paul (1909). Parliamentary Government in Chile.The American Political Science Review, Vol. 3, No 4, pp. 507-538.

Rock, David (1975). Politics in Argentina, 1890-1930: The rise and fall of radicalism. Cambridge, England: Cambridge University Press.

Romero, Luis Alberto (2002). A history of Argentina in the twentieth century. University Park: Pennsylvania State University Press.

Schamis, Héctor (2002). Argentina: Crisis and Democratic Consolidation. Journal of Democracy Vol. 13, No 2, pp. 81-94.

Scully, Timothy (1992). Rethinking the Center: Party politics in nineteenth-and twentieth-century Chile. Palo Alto: Stanford University Press. 
Thelen, Katheleen (2003). How Institutions evolve: Insights from Comparative Historical Analysis. In Mahoney, James and Rueschemeyer, Dietrich; Comparative historical analysis in the Social Sciences. New York: Cambridge University Press.

Thelen, Kathleen y Steinmo, Sven (1992). "Historical Institutionalism in comparative politics". En Steinmo, Sven and Thelen, Kathleen. Structuring Politics: Historical Institutionalism in Comparative Analysis. New York: Cambridge University Press.

Taylor, Lucy (1998). Citizenship, participation and democracy: Changing dynamics inChile and Argentina. New York: Saint Martin's Press.

Tsebelis, George (1990). Nested Games: Rational Choice in Comparative Politics. Berkeley: University of California Press.

Zakaria, Fareed (2003). The Future of Freedom: Illiberal Democracy at Home and Abroad. New York: Norton Press. 